\title{
Ready or not: Kindergarten classroom engagement as an indicator of child school readiness
}

\begin{abstract}
Children's preparedness for school is an important predictor of their eventual academic attainment, health, and personal success well into adulthood. Although kindergarten knowledge of numbers and vocabulary represent robust indicators of children's readiness to learn at school entry, theory and research suggest that selfdirected learning skills are also important in meeting the challenges of the elementary school classroom. This review examines evidence related to the potential benefits (e.g. improving children's academic outcomes) of targeting classroom engagement skills, a person-environment fit characteristic reflecting task-orientation and industriousness. Reviewed studies suggest that classroom engagement skills are malleable and robust predictors of later elementary school achievement. Research also suggests that cognitive control skills in the form of executive functions are likely to underlie individual differences in classroom engagement. This paper provides evidence that developing pre-school and kindergarten curriculum that target cognitive control can be a useful strategy for enhancing student engagement behaviour. Developing early interventions that bolster school readiness can then help circumvent risks for later academic and social impairments in childhood and adolescence.
\end{abstract}

Keywords: school readiness; cognitive control; classroom engagement; learningrelated behaviour; academic achievement; psycho-social adjustment.

Caroline Fitzpatrick, New York University, Research Fellow, Centre for Education Practice Research, University of Johannesburg. E-mail: caroline.fitzpatrick@umontreal.ca.

South African Journal of Childhood Education | 2012 2(1): 1-32 | ISSN: 2223-7674 | ๑ UJ
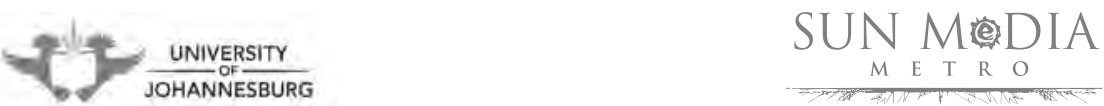


\section{Introduction}

Making sure that the next generation of citizens, workers, and caregivers benefit from a basic education remains at the forefront of societal concerns. For example in Canada, the Québec Ministry of Education holds the mission of providing all children with the opportunity to acquire skills that will help them develop into contributing members of society (MELS, 2010). In addition to representing an important objective from a social policy standpoint, maximising the educational qualifications of each individual child also figures prominently on the economic agenda. Cost-benefit analysis research has highlighted the tremendous economic burden of underachievement and high-school dropout, which are as high as 34\% among 17 year olds in the province of Québec, Canada (MELS, 2005). In light of aging population demographics, the province of Québec particularly depends on individual reinvestment in order to support social programmes for the next generation. In order to develop efficient intervention strategies aimed at improving high school completion, it remains important to identify modifiable child and family characteristics which can be targeted to bring about improvement in student achievement.

\section{The importance of school readiness}

The process leading to high school dropout originates early on in children's academic trajectories. For instance, child characteristics in kindergarten forecast successful academic trajectories and persistence through high school completion (Entwisle, Alexander \& Olson, 2005). One way to increase academic proficiency is to help children begin school fit for the challenges they will face throughout their educational journey. Indeed, there has been growing concern over the idea that children need to be well prepared at school entry in order to prevent them from falling behind (High \& The Committee on Early Childhood, Adoption, and Dependent Care and Council on School Health, 2008; Tramontana, Hooper \& Selzer, 1988; Zuckerman \& Halfon, 2003). School readiness refers to child maturity and ability to negotiate classroom demands upon transitioning to formal schooling. A child that is ready to learn is capable of fully participating in the educational and social aspects of the kindergarten classroom. Theoretically, school readiness is a malleable outcome of early childhood life experiences and development (High \& The Committee on Early Childhood, Adoption, and Dependent Care and Council on School Health, 2008). The promotion of school readiness has, therefore, become an important social preoccupation because of its potential for bettering the lives of individuals, communities, and society.

Interest and perspectives on school readiness have simultaneously emerged across academic disciplines. For economists, identifying which early capabilities predict achievement and employment potential represents an important investment from a human capital perspective (Duncan et al., 2007; Heckman, 2006; Murnane, Willett \& Levy, 1995). Underachievement especially represents a costly social problem (Knudsen, Heckman, Cameron \& Shonkoff, 2006). Medical practitioners have emphasised the importance of school readiness from a population health perspective, 
drawing attention to the relationship between educational attainment and later health, morbidity, and mortality (Fiscella \& Kitzman, 2009; Freudenberg \& Ruglis, 2007). Furthermore, paediatric perspectives have proposed more integrative and contextual definitions of school readiness. That is, in addition to individual characteristics some have argued that schools and communities also need to be involved in supporting children through a successful transition (High \& The Committee on Early Childhood, Adoption, and Dependent Care and Council on School Health, 2008; Zuckerman \& Halfon, 2003). Finally, policy makers propose that international goals should include universal school readiness and proficiency upon school entry. Such reasoning is behind the highly publicised No child Left Behind act adopted in the United States of America.

Over the past half century, a lot of research has been allocated to identifying child characteristics that forecast success in early schooling (Duncan et al., 2007; Grissmer, Grimm, Aiyer, Murrah \& Steele, 2010; Pagani, Fitzpatrick, Archambault \& Janosz, 2010; Romano, Babchishin, Pagani \& Kohen, 2010). The rationale for this focus is rooted in the notion that how one begins school predicts rewards or consequences for individuals, their families, and society at large. Research supports the claim that children who begin their academic journey on solid ground experience more academic success in primary school (Duncan et al., 2007). In contrast, children who experience difficulty early on are more likely to embark on a course of academic underachievement associated with an increased risk of dropping out of school (Alexander, Entwisle \& Dauber, 1993; Alexander, Entwisle \& Horsey, 1997). Youth who decide to drop-out of high school are then more likely to experience poorer health and engage in risky and antisocial behaviours including unprotected sexual intercourse, substance use and abuse, and involvement in criminal activity (Ellickson \& McGuigan, 2000; Freudenberg \& Ruglis, 2007; Hargreaves et al., 2008). Understanding what skills contribute to successful school experiences is therefore an important step for helping both children and their families achieve their maximum potential.

In a large scale international study of school readiness, Duncan et al. (2007) provide evidence that skills in math, reading, as well as attention, are important predictors of later academic achievement. Though previously hypothesised as important contributors to school adjustment (Ladd, Birch \& Buhs, 1999), child classroom behaviours, such as aggression, prosocial skills, and anxiety, were not statistically significant. A major conclusion from these findings is that child behaviours carry less weight in facilitating academic success than early intellectual skills.

The findings of Duncan and colleagues have been replicated using a French Canadian sample (Pagani et al., 2010). Surprisingly, even though the replication presented methodological improvements over the original piece, a remarkable similarity in effect sizes was observed in both studies. Going beyond the Duncan et al. model, learning-related behaviours in terms of classroom engagement reflecting taskorientation and effortful control were addressed as additional outcomes. Kindergarten math and attention skills predicted second grade classroom engagement. This study did not address the origins of classroom engagement, as such the role of kindergarten 
learning-related skills for school readiness has received less attention. In particular it would be interesting to examine if engaged kindergarten students fare better later in elementary school.

Even though knowledge of numbers and vocabulary explain a lot of the variance in achievement (Duncan et al., 2007), they leave out a theoretically meaningful selfdetermining component. In order to be successful in the classroom, children also need to develop strong learning skills and remain engaged in the classroom if they are to fully benefit from instruction and learning experiences (Bierman et al., 2008; Fredricks, Blumenfeld \& Paris, 2004). Recently, the importance of engagement reflecting commitment and persistence toward learning and academic goals has received attention as a promising target for interventions aimed at reducing student dropout and poor academic achievement (Fredricks et al., 2004; Janosz, Archambault, Morizot \& Pagani, 2008). A chief benefit of studying engagement resides in the intuitively appealing notion that engagement is directly related to learning, as well as in the idea that engagement, unlike IQ or family socio-demographics, is malleable and amenable to change (Fredricks et al., 2004). Moreover, an interest in child learning behaviour is also consistent with many educational reform policies. The acquisition of reading, writing, and mathematics skills remain key domains of child performance. However, the ability to get along and cooperate with fellow students, follow rules and instructions, and work autonomously has been integrated within the grading schemes used to evaluate performance of elementary school students.

In the present review, we propose a model of school readiness that addresses the unique contribution of self-directed learning behaviour to children's academic potential. In particular, we examine how classroom engagement behaviour reflecting the ability to follow procedures, remain on-task, and adapt to the demands of the classroom plays a role in setting the course for successful academic trajectories. We also examine how early life experiences contribute to school entry classroom engagement, and subsequent patterns of engagement across elementary school.

\section{Definitional issues}

Though the concept of engagement has been defined and operationalized in a number of ways in the education literature, commonalities across studies include a definition of engagement as a reflection of the person-environment fit (Fredricks et al., 2004). In this light, an individual's ability to benefit from instruction and be successful in school may dependent not only on how much they know at school entry, but also on their mastery of skills that favour adaption to the norms and demands of the classroom. For example, children who demonstrate self-directed behaviour that favours learning and involvement in the classroom are likely to be more successful and illicit more positive reactions from teachers (Pianta, 2009). Children with these favourable characteristics are likely to be rewarded for their behaviour by teachers, which can further reinforce positive classroom behaviour in the future (Skinner \& Belmont, 1993). From a contextual or systemic approach, changes in engagement are likely to arise through 
interventions that target relevant characteristics of the child, their environment, or both.

One recent empirically driven conceptualisation from educational science has been useful in advancing our understanding of the nature and potential usefulness of engagement as an indicator of school readiness. Based on a thorough review of the education literature, Fredericks et al., (2004) conclude that engagement is a multifaceted concept with emotional, cognitive, and behavioural components. As a result, this definition helps organise a wide range of behaviours, which, if targeted, can improve academic performance. Furthermore, this distinction can guide the development of more refined risk profiles for detecting children who may be facing poor academic achievement and dropout. When broken down into affective, behavioural and cognitive components, high school engagement trajectories are reliable predictors of high school student's eventual attainment and high school completion (Archambault, Janosz, Fallu \& Pagani, 2009; Janosz et al., 2008).

Although Frederick's rigorous review of the literature has highlighted the potential usefulness of adopting a multi-faceted conceptualisation of engagement, a more behavioural measure of engagement is useful for examining this trait in elementary school students. First, it provides a distal but ecologically meaningful demonstration of self-regulation that can be easily observed by kindergarten teachers. Second, behavioural engagement, such as being on-task, also presupposes a certain amount of cognitive and emotional engagement. Poor control of emotions and the inability to effectively direct attentional resources to classroom tasks are disruptive to on-task behaviour (Rothbart \& Bates, 2006). Third, a focus on behavioural engagement is more appropriate given the developmental stage of elementary school children. Most of the work which has examined affective and cognitive engagement was conducted with older elementary and high school students. As a result, affective and cognitive engagement defined in terms of child attachment to the school, participation in extra-curricular activities, and preference for enriched classes and exercises may not represent meaningful indicators of engagement in young elementary school students. Finally, the present focus on behavioural engagement is consistent with sociological theories of individual success. Positive work-habits and the willingness to conform to rules and instructions in the childhood learning context are important because they are akin to the skills required for success in the adult workplace. For example, a review of literature in sociology, conducted by Farkas (2003), suggests that adults who possess a combination of learning skills that reflect respect for authority, initiative, task-orientation as well as the ability to follow rules and procedures experience greater occupational and personal success. These findings are consistent with the current conceptualisation of classroom engagement. 


\section{Theoretical perspectives on school readiness and classroom engagement}

\section{School readiness}

In retrospect, research on school readiness has been driven by the immediate needs of social policy more so than carefully constructed theory. This may be due to the demand placed on policy makers to increase the overall quality of education to solve urgent social problems. Nevertheless, there are several theoretical and empirical considerations that should be taken into account in methodological and conceptual approaches to school readiness.

School entry coincides with an important transition in children's cognitive development. According to Piaget (1956), an important cognitive shift occurs around the age of six, which serves as the basis for complex thinking and cognitive processing. One implication of Piaget's stage-driven theory of development is that only cognitively mature children will be able to acquire classroom lessons demanding more complex mental operations. Conversely, less cognitively mature children may experience difficulty in school. Cognitive neuroscience research also suggests that important stage-like changes in child cognition emerge during the pre-school period (Feldman, 2009; Marcovitch \& Zelazo, 2009; Zelazo \& Frye, 1998). For instance, in response to rapid brain development during the first years of life, children become much more proficient at using focused attention and working memory to solve problems (Feldman, 2009; Garon, Bryson \& Smith, 2008; Marcovitch \& Zelazo, 2009). These improvements in attention and working memory in early childhood forecast children's subsequent use of inhibitory control, which emerges later in the pre-school years (Feldman, 2009). Consequently, by school entry children are generally capable of exercising effortful control over behaviour and delayed gratification in the pursuit of goals (Mischel, Shoda \& Rodriguez, 1989).

According to neurocognitive theories, a window of relative plasticity is also likely to help children more easily acquire new behaviour, knowledge, and skills during early childhood. The remarkable success of carefully designed pre-school interventions programmes supports the existence of a developmentally sensitive period for learning (Diamond, Barnett, Thomas \& Munro, 2007; Gormley, Phillips \& Gayer, 2008; Heckman, 2006). Although theories of plasticity do not suggest that new learning cannot occur outside of this period, they do suggest that a stronger environmental push may be needed outside of this timeframe to bring about improvement in children's cognitive and social skills. Because interventions that occur later in childhood and adolescence usually require more resources, they are viewed as less cost-effective (Heckman, 2006; Knudsen et al., 2006).

\section{Classroom engagement}

Concepts across several theoretical perspectives are relevant to the proposed definition of classroom engagement. For one, classroom engagement falls into the 
broad category of self-regulation processes, which encapsulate the combination of cognitive and emotional strategies individuals use to influence their own internal states, thoughts, and behaviours (Rothbart \& Bates, 2006). Self-regulation is likely to support classroom engagement behaviour by facilitating self-initiated responses, such as those that require effortful control, delay of gratification, self-control, and self-discipline. The present definition of classroom engagement also bares similarity to motivational concepts described in Deci \& Ryan's self-determination theory (2008). In particular, classroom engagement is likely to partially reflect identified motivation, which refers to the capacity to remain on-task and perform deliberate, effortful, and challenging exercises, even in the absence of pleasure or enjoyment.

Blair and Diamond (2008), describe school entry competence as the result of multiple interacting child and family level systems (e.g. gene expression, parenting, cultural norms, etc.). These interrelations are described as interacting and dynamic because similar risk factors are likely to give rise to different outcomes according to their context. For example, Blair and Diamond make excellent reference to the case of the catechol-O-methytransferase [COMT] gene whose common expression is associated with better cognitive control and executive functioning. In particular, this gene tends to result in higher levels of dopamine in the prefrontal cortex. Approximately $25 \%$ of individuals possess a variant of this gene, which leads to faster clearing of dopamine in the prefrontal cortex. This genotype is associated with poorer performance on cognitive control tasks. However, more dopamine in the prefrontal cortex also makes individuals more responsive to stress. As a result, individuals who possess the variant of this gene, resulting in lower levels of dopamine in the prefrontal cortex, are expected to perform better on cognitive tasks under conditions of moderate stress. By contrast, this scenario is reversed for the majority of children under non stressful conditions (Blair \& Diamond, 2008).

Blair and Diamond's model also helps clarify a mechanism through which emotional and cognitive dimensions of self-regulation can mutually influence each other and ultimately classroom behaviour. Cognitive control, or executive functions consists of the inhibition of inappropriate responses, working memory ability, and attentional control (Garon et al., 2008; Miyake et al., 2000). These skills, which are governed by the prefrontal cortex, play an important role in sustaining children's goal directed behaviour in the classroom (Barkley, 1997; Blair \& Diamond, 2008). To be successful in the classroom, children must inhibit unfavourable behaviours, use working memory to solve problems and answer questions, and exercise control over attention, in order to remain responsive to changing instructions and contextual constraints. Emotional regulation, in turn, represents the ability to modify the experience of emotions to meet contextual demands. These skills, which involve regulating one's own states and exercising wilful control over behaviour, can also help support engagement in the classroom. This means that cognitive control skills may both influence emotional outcomes, as when children inhibit feelings of frustration, and be influenced by them, as when anxiety impairs concentration. For young students, the ability to optimise arousal and positive affect, much like reducing negative emotions, is also likely to 
improve academic performance. For example, mild levels of test anxiety have been shown to benefit cognitive performance (Lupien, Maheu, Tu, Fiocco \& Schramek, 2007).

Preschooler cognitive control skills have been linked to academic achievement and psychosocial function in later childhood. Foremost is the link between executive function and math performance (Blair \& Razza, 2007; Bull \& Scerif, 2001; Butterworth, Varma \& Laurillard, 2011; Cirino, 2010; Sabbagh, Xu, Carlson, Moses \& Lee, 2006). Other research suggests a strong link between cognitive control and writing skills (Altemeier, Abbott \& Berninger, 2008; Altemeier, Jones, Abbott \& Berninger, 2006). Furthermore, pre-school children who are better able to exert effortful control to delay gratification score higher on cognitive achievement tests several years later in adolescence (Mischel et al., 1989).

Children who are experiencing difficulty in the area of cognitive self-regulation are also at risk of facing impairments in psychosocial and interpersonal domains. Eisenberg and colleagues (2001) have shown that four- to eight-year-old children who experience difficulties in effortful control are more likely to display internalising and externalising problems in later childhood. Similarly, children who display unstable or low levels of cognitive control (i.e. the ability to resist distractions and temptations) between the ages of five and 10 subsequently show more elevated trajectories of externalising problems (Zhou et al., 2007). Finally, children who demonstrate low levels of effortful control self-report more delinquency and convictions by age 21 (Henry, Caspi, Moffitt, Harrington \& Silva, 1999).

Research, employing a person-centered approach, suggests that school-aged children diagnosed with ADHD are more likely to show multiple impairments in academic, social, behavioural, and emotional domains (Lee, Lahey, Owens \& Hinshaw, 2008). This is not surprising given that poor cognitive control represents a central impairment in ADHD (Barkley, 1997). Furthermore, in a sample of adolescents, ADHD symptoms were associated with impairments in expressive, receptive, and written communication ability, as well reductions in the ability to engage in social interactions, be responsible, and show sensitivity towards others (Clark, Prior \& Kinsella, 2002).

Classic developmental theories also suggest an important role for classroom engagement in positive child adjustment. According to Russian developmental psychologist Lev Vygotsky (1987), the ability to self-regulate and remain engaged, depends on children's ability to master and eventually internalise speech. More specifically, the development of childhood self-control skills involves a developmental progression from the use of 'outloud', non-specific language, to the use of 'private', internalised language, to guide goal-directed behaviour (Vygotsky, 1987). This process is believed to occur within an 'open system', which suggests interactions with the environment can facilitate children's acquisition of private speech and eventually selfcontrol (Cicchetti, 1984). Once children are capable of internalising speech, they can more efficiently use language to give themselves instructions during the performance of complex problems. They may also find it easier to persist in the face of distractions, 
regulate emotional responses, and inhibit inappropriate behaviours in the classroom. Research on child temperament also supports the idea self-regulation develops in part through fruitful interactions with caretakers (Rothbart \& Bates, 2006).

The American sociologist Erik Erikson's notion of industriousness, which refers to children's ability to learn skills required for participation in adult society, is also consistent with the present conceptualisation of engagement. According to Erikson's theory of identity development (1950), the period from age 6 to 11 is characterised by environmental and social demands placed on the child to develop strong work habits and industriousness. Some children may fail to meet the social demands of the classroom because they lack the requisite skills to regulate their cognitions and emotions. These children, in turn, may be at risk of experiencing poor achievement and feelings of inadequacy or inferiority, which may manifest themselves as psychosocial adjustment problems later in life. In line with this view, others have argued that children who experience difficulty adjusting to the demands of the kindergarten classroom are likely to develop perceptions of themselves as being incompetent, which can undermine future academic adjustment and motivation (Blair \& Diamond, 2008; Deci \& Ryan, 2008). Evidence supports this hypothesis as early school failure that results in grade retention is associated with persistent academic and psychosocial problems toward emerging adolescence (Pagani, Tremblay, Vitaro, Boulerice \& McDuff, 2001).

Finally, it is interesting to note that child engagement is related to American criminologists Gottfredson and Hirshi's notion of self-control and social bonds (1990). According to social control theory, children who are engaged in school, and willing to invest time and effort in completing their work and attaining good grades, are unlikely to become involved in delinquent behaviours. By contrast, poor attachments and bonds with others, such as peers and teachers, and reduced involvement with conventional institutions, such as schools, are believed to erode individual self-control. Low self-control, in turn, is believed to mediate future involvement in antisocial and deviant behaviour (Moffitt \& Henry, 1989; Wright, Caspi, Moffitt \& Silva, 1999). In this sense, classroom engagement can be interpreted as an index of children's capacity to integrate and conform to the social norms and values of society.

In summary, converging theory and research suggest that productive learning behaviours represent important indicators of children's academic potential. Definitions of engagement have been useful in clarifying the range of behaviours that can be measured as indicators of engagement (Fredricks et al., 2004). Finally, Blair and Diamond's developmental model has enhanced our understanding of the potential dynamic interplay of emotional and cognitive processes in children's regulation of classroom engagement.

\section{Expanding Duncan's school readiness model}

Because of its large sample size and methodological rigor, Duncan and colleagues' (2007) model of school readiness has become a benchmark in school readiness 
research. Despite its empirical usefulness it does present three important limitations. First, a general finding of research using this model is that kindergarten entry behaviours, with the exception of attention problems, are not predictive of later success. This conclusion should be interpreted with caution, since the authors only assessed a restricted range of mostly negative or problematic child behaviours. It would have been equally, if not more, informative to examine productive learningrelated skills, such classroom engagement as opposed to child internalising (i.e. anxiety) and externalising (i.e. physical aggression) problems. A second limitation of Duncan's model is that only academic success was considered as a pertinent outcome of interest. However, it is plausible that school readiness forecasts future adjustment in multiple spheres of child functioning. Furthermore, children need to develop a variety of competencies, including positive psychosocial skills and strong work habits on the road to high school completion and successful transition to adulthood. For these reasons it is useful to consider a holistic set of child functioning indicators as outcomes of school readiness. A third limitation of Duncan's model is that it does not help us understand the origins of children's successful adjustment to school. Understanding this developmental chain of events is essential to maximise pre-school intervention and prevention strategies.

Re-evaluating and expanding definitions of school readiness can help us better identify children at risk of future academic problems. Reliable school readiness models can also be used in the development of head start programmes for pre-schoolers. Thus, to achieve universal school proficiency starting in the first grade, it is important to ensure that our definition of school readiness encompasses a comprehensive range of skills that support child learning and adaptive psychosocial functioning across development.

\section{Classroom engagement and achievement}

Classroom engagement incorporates elements of task-orientation, atentiveness, cognitive control, and behavioural regulation. Accumulating evidence suggests these skills can reliably predict later academic performance (McClelland, Acock \& Morrison, 2006; McWayne, Fantuzzo \& McDermott, 2004; Pagani et al., 2008). In the following section we review evidence supporting an association between kindergarten classroom engagement skills and achievement in later elementary school.

Using a sample of 200 pre-schoolers enrolled in a Head Start programme, McWayne and colleagues examined which child skills were predictive of later achievement (2004). At around the age of five, children completed several scales to assess their preparedness for kindergarten learning. These included measures of preacademic skills in terms of literacy and numeracy, motor development, quality of peer interactions and learning-related behaviours reflecting attention and persistence, motivation and competence, and attitudes towards learning. The following year, children completed the Early Screening Inventory designed to detect children at risk for developmental and academic problems. Results revealed that pre-academic 
skills and learning-related behaviours were the only significant predictors of later achievement. These associations were observed above and beyond the quality of children's Head Start classroom and neighbourhood characteristics.

In another study, authors examined whether kindergarten learning behaviour predicted individual patterns of academic achievement across the elementary school years. Using a large sample of children followed longitudinally from kindergarten through Grade 5, Li-Grining and colleagues (2010) found that child learning skills reflecting task-orientation, autonomy, and attentiveness were associated with later achievement trajectories across the elementary school years. Furthermore, this association did not differ between children on the basis of socio-economic status and ethnicity. McClelland and colleagues (2006) also examined how learning skills predicted achievement across elementary school. The authors found that kindergarten students who showed higher levels of productive work habits, achieved more academic success in Grades 1 through 6. More engaged children also showed steeper increases in academic achievement in the early elementary school years. The achievement gap between children with higher and lower levels of kindergarten engagement appeared to remain rather stable until the end of elementary school. Furthermore, the association between learning behaviour and patterns of engagement was observed above and beyond the potentially confounding influence of child IQ, ethnicity, and maternal education. Finally, in a study which followed children from the ages of five through to the age to 13, Ladd and Dinella (2009) observed that compared to children who showed active participation and engagement in the classroom, children who were more resistant to following instructions were more likely to show maladaptive patterns of achievement during the transition to secondary education.

Other research also suggests a strong role for learning-related behaviour in academic success. First grade students who participate and are more involved in the classroom tend to do better on fourth grade academic measures (Alexander et al., 1993). Kindergarten task-orientation and persistence have been shown to explain the relationship between early aggressive and prosocial behaviours and first grade math and reading achievement (Normandeau \& Guay, 1998). Duncan et al., (2007) found that teacher-ratings of poor attention control represent key components of school readiness that reliably forecasts later academic success above and beyond a large set of child and family characteristics. Teacher-ratings of attention problems can also explain unexpected trajectories of academic failure (Pagani et al., 2008). Finally, later on in adolescence, student self-control explains the gender gap in achievement (Duckworth \& Seligman, 2005).

In sum, several studies have defined learning-behaviours as encompassing components of classroom engagement such as autonomy and self-regulation. Studies have tended to show that these productive work behaviours measured as early as kindergarten, are associated with achievement outcomes in later elementary schools. These predictive relationships appear to be robust and can be observed above and beyond potentially confounding child and family demographic characteristics. 


\section{Academic performance: Is achievement all that matters?}

Achievement outcomes have represented a singular focus in much of the school readiness literature. This is surprising from both a theoretical and practical perspective. For one, in addition to forecasting academic outcomes, kindergarten classroom engagement skills are also likely to predict adaptive psychosocial functioning in later childhood. Furthermore, from a pragmatic perspective, the omission of psychosocial outcomes in school readiness research is unfortunately given that social and interpersonal skills are key ingredients for success throughout schooling and eventually in the labour market (Almlund, Duckworth, Heckman \& Kautz, 2011; Heckman, 2007).

Empirical research has shown that children who show poor engagement in the classroom are likely to develop more conflictual relations with teachers and peers. Poorly regulated disruptive children are also more likely to undermine group functioning, experience social rejection, and develop poor academic motivation (Ladd, Birch \& Buhs, 1999; Chen, Huang, Chang, Wang \& Li, 2010; Vitaro, Brendgen, Larose \& Tremblay, 2005). By contrast, the cognitive control skills that underlie children's ability to remain engaged in the classroom are likely to contribute to positive psychosocial adjustment. Children's ability to control attention can contribute to the successful inhibition of inappropriate emotional responses. In particular, better cognitive control can help children direct attention away from negative emotions (Rothbart \& Bates, 2006). On the other hand, temperamental dispositions towards emotional reactivity can compromise the quality of children's social interactions. For example, it can interfere with child ability to effectively focus and shift attention to appropriate social cues during social exchanges. The ability to cooperate with other children to complete classroom activities is a key determinant of children's academic adjustment. Failure to mobilise attention towards decoding the states of others is likely to lead to interpersonal conflict, peer rejection, and academic adjustment problems.

Examining children's holistic development also makes sense for practical reasons. Children need to develop a variety of competencies, including positive psychosocial skills and strong work habits, on the road to high school completion and the successful transition to adulthood. Non-cognitive or social skills, not typically measured by ratings of achievement, remain important predictors of how children will fare in their future personal and professional relationships. In the workplace, adults who develop more positive interpersonal orientations are likely to achieve more occupational success, even once their cognitive ability is taken into account (Almlund et al., 2011; Farkas, 2003; Heckman, 2007). As a result, to benefit societal investment, a public educational system should help students prepare for their future roles as citizens, workers, parents, and health-care users. In light of this, the usefulness of a school readiness model could benefit from its ability to predict positive psychosocial skills in addition to academic achievement in math and reading.

There is some preliminary evidence that children who have difficulty remaining engaged in kindergarten are more likely to experience a wide range of adjustment 
problems by the end of elementary school (Fitzpatrick, 2012). In a representative population-based sample, one study examined the association between kindergarten classroom engagement skills and a wide range of child academic and psychosocial adjustment indicators by the end of elementary school. Kindergarten students who were rated by teachers as more engaged as defined by the tendency to work autonomously, follow directions, and remain attentive showed higher levels of academic achievement, had more positive relations with teachers, and showed less symptoms of problematic aggressive and antisocial behaviour by the fourth grade. Associations remained significant after controlling for kindergarten literacy and math skills and symptoms of behaviour problems. Furthermore, these results did not differ on the basis of gender or family background characteristics.

\section{Early predictors of classroom engagement}

To date, few studies have empirically addressed the developmental origins of classroom engagement (Shonkoff \& Phillips, 2000). Given the importance of cognitive control and early attention control in the pursuit of goal-directed behaviour (Barkley, 1997; Rothbart \& Bates, 2006), it is likely that early childhood cognitive development forecasts school entry engagement. One possibility is that heterotypic continuity exists in cognitive control ability from the early pre-school years to age five, whereby early cognitive control skills culminate in better classroom engagement at school entry (Putnam, Rothbart \& Gartstein, 2008). From an intervention perspective, better understanding this developmental chain remains an important goal for enhancing school readiness in at-risk children.

Furthermore, as suggested by ecological and transactional theories of child development (Blair \& Diamond, 2008; Bronfenbrenner, 1986; Rothbart \& Bates, 2006; Vygotsky, 1987), it is likely that the development of cognitive control is influenced by children's early environment and experience with caretakers. In particular, supportive parenting that is aimed at helping children sustain attention during activities is likely to help children develop strong attention control skills (Belsky, Pasco Fearon \& Bell, 2007; Razza, Martin \& Brooks-Gunn, 2010). Research on individual differences in temperament also suggest that while genetic differences exist in attention from infancy onward, early parent child interactions also play a role in helping children develop sustained attention (Rothbart \& Bates, 2006). Additional family characteristics, such as maternal stress and social support, might also influence the development of positive learning-related behaviour at school entry (Razza et al., 2010). High levels of maternal stress are related to an increased incidence of attention problems in middle childhood (Barry, Dunlap, Cotten, Lochman \& Wells, 2005). As a result, it would be informative to examine whether mothers' experience of stress and social support during the pre-school years are associated with poor classroom engagement skills in children during elementary school.

Research provides some evidence that cognitive control skills represent developmental precursors to classroom engagement behaviour in elementary school. 
For example, Mathews and colleagues (2009), found that child behavioural selfregulation skills at age five predicted early academic performance. In another study by Blair and Razza (2007), pre-school self-regulation skills in the form of effortful cognitive and attention control predicted school entry competence in math and reading. In another study, authors examined whether cognitive control skills in children as young as 3 could predict school readiness. After controlling for the potentially confounding effect of socio-economic status and child intellectual ability, working memory skills predicted unique variance in kindergarten classroom engagement, number knowledge, and receptive vocabulary skills (Fitzpatrick \& Pagani, 2011). Another study examined how sustained attention skills and parental factors at age three contribute to kindergarten school readiness. In both poor and near poor children, better sustained attention and lower impulsivity predicted receptive vocabulary scores at school entry. The only parental characteristic associated with later verbal skills was maternal hostility. Similar results were obtained by Fitzpatrick (2012). In this study, patterns of child engagement across elementary school were predicted from toddler working memory skills and lower levels of impulsivity. Furthermore, similar to what was found by Razza et al., maternal hostility was the parental characteristics most strongly associated with child eventual adjustment to school. Finally, in line with ecological models of development, mothers' experience of stress, and perceptions of social support also predicted children's learning trajectories across elementary school.

\section{Discussion}

Children's ability to follow directions, work autonomously, and remain focused in the classroom setting represent useful indicators of their preparedness to meet the demands of formal schooling which begins in the first grade. In particular, literature suggests that classroom engagement skills are related to later achievement in mathematics and reading several years later (Daniels et al., 2008; Fitzpatrick, 2012; Ladd \& Dinella, 2009; McClelland et al., 2006; McWayne et al., 2004). Engagement skills may be related to these later outcomes, because they facilitate adaptation to the academic and social demands of the early school environment. They are also likely to reflect underlying individual differences in self-regulation skills, which play an important role in helping individuals adjust to novel challenges.

Poor engagement is also related to indicators of child psychosocial adjustment. For one, it predicts more conflict with teachers. Children who were less engaged in the classroom also appeared to use more aggressive and antisocial behaviour while interacting with fellow students (Fitzpatrick, 2012; Ladd et al., 1999; Razza, Martin \& Brooks-Gunn, 2010). The quality of relationship students develop with grade school teachers can have important repercussions on children's subsequent academic trajectories. Teachers may be less inclined to exert effort and provide guidance to challenging students. Furthermore, elementary school teachers in particular, spend a lot of time with the same children for whom they play a role as both a nurturer and 
educator. As a result, teacher's expressions of warmth/closeness or anger/conflict over the course of a school year can shape children's school and learning experience. In particular, much like good parenting skills, teacher warmth and structure are likely to enhance child outcomes; whereas conflictual relations with teachers are likely to steer children toward less positive learning trajectories (Baker, 2006; Brendgen, Wanner \& Vitaro, 2006; Hamre \& Pianta, 2001; Rimm-Kaufman, La Paro, Downer \& Pianta, 2005). Once established, teacher expectations of their students can then influence later student achievement, even when past performance is taken into account (Rosenthal \& Jacobson, 1968).

An association between classroom and psychological adjustment, from a prevention perspective, is of concern. Elementary school students who perpetrate proactive acts of aggression are at an elevated risk of following a course characterised by involvement in later criminal and antisocial behaviour (Nagin \& Tremblay, 1999). Furthermore, children who present externalising problems are more likely to be excluded from their peer group (Ladd et al., 1999; Vitaro et al., 2005). Disruptive children are also more likely to experience rejection or victimization, especially if the larger social group labels them as 'unpopular'. By contrast, children who show lower levels of behavioural problems are likely to develop more supportive relations with peers. These children are then more likely to be included in classroom activities, which can increase positive feelings towards school and access to social and academic learning opportunities.

Overall, the evidence reviewed regarding the value of classroom engagement is useful for several reasons. Academic achievement tends to stabilise in the middle of elementary school. Youth who are experiencing difficulty in primary school are therefore more likely to follow a path leading to underachievement and high school dropout (Alexander et al., 1993). Dropping out of high school is subsequently associated with a cascade of risks that can impede wellbeing throughout the life course. For example, the decision to drop-out of high school increases the risk of lifelong poverty (Card, 1999), poorer health (Freudenberg \& Ruglis, 2007), and antisocial life-course trajectories (Henry et al., 1999). Consequently kindergarten measures that forecast achievement in the fourth grade represent useful tools for identifying children at risk of lifelong adjustment problems.

There is also evidence that early childhood cognitive control is a robust predictor of engagement in elementary school. These findings suggest that early interventions that strengthen attention control and working memory, two important mechanisms of learning, can significantly improve school readiness. Furthermore, some research suggests that parental characteristics can influence childhood engagement trajectories (Razza et al., 2010; Fitzpatrick, Barnett \& Pagani, unpublished data). These observed associations relating the larger family ecology to child learning outcomes suggest the importance of providing support to at risk-families in order to reduce academic underachievement. 
The findings of the present review can be interpreted within a larger selfregulation framework. According to developmental theories, an individuals' capacity to effectively manage their inner states and cognitions plays an important role in helping them meet the demands of their social and work environments (Barkley, 2004; Rothbart \& Bates, 2006). Though children's development of self-regulation is partially due to maturation, early environments and experiences with caregivers can also shape its course (Bernier, Carlson \& Whipple, 2010; Shonkoff \& Phillips, 2000). Given the notion of heterotypic continuity, early individual differences in attention control and temperament are likely to manifest themselves as greater task-orientation and classroom engagement by the time children enter school (Putnam et al., 2008; Rothbart \& Bates, 2006). Furthermore, initial differences in cognitive control can help children develop the ability to mobilise attention in the service of emotional regulation, which in turn can be beneficial for sustaining concentration in stressful or frustrating situations. Better emotional regulation can also facilitate positive social interactions (Rothbart \& Bates, 2006). From a developmental perspective, early failures and successes are also likely to influence children's beliefs about their level of competence, which can then have an impact on their motivation to succeed (Deci \& Ryan, 2008). In particular, early difficulty with engagement and academic performance may undermine child motivation, which can then predispose children to embark on stable low trajectories of classroom engagement. The possibility of such a feedback loop strongly suggests the importance that making sure children are ready to learn at school entry for the prevention of well-being and academic problems.

\section{Implications}

\section{Curriculum and classroom engagement}

Historically, schooling policies have functioned primarily to ensure a steady inflow of workers to fuel the labour market (Lillard, 2005). For efficiency purposes, children were asked to assimilate large amounts of knowledge passively from teachers. In this context, little emphasis has been placed on problem-solving, creativity and autonomous learning. Classrooms, teaching styles, and curricula were standardised with a one size fits all formula. While this form of classroom arrangement is well suited for its intended purpose of developing workers for the industrial market, social and technological transformations over the past century have changed the nature of working conditions. For this reason, the 'factory model' of learning can be seen as increasingly ill-suited for current market characteristics, which favour workers that are skilled learners capable of flexible problems-solving skills (Knudsen, Heckman, Cameron \& Shonkoff, 2006). Traditional kindergarten classrooms are likely to be especially inefficient for the promotion of flexible learning and classroom engagement in young children during a developmental period that favours creativity.

Interventions and curricula that target pre-school children represent promising avenues for increasing school readiness and adjustment throughout childhood 
(Heckman, 2006). Few programmes, to date, have been designed to specifically improve cognitive control and classroom engagement in pre-school aged children. Nonetheless, Tools of the Mind pre-school programme (Bodrova \& Leong, 2007), Montessori Education (Lillard \& Else-Quest, 2006), and the REDI programme (Bierman, Domitrovich et al., 2008; Bierman, Nix, Greenberg, Blair \& Domitrovich, 2008) have been designed to improve child cognitive control and classroom learning behaviour. Other programmes have included child self-regulation components within larger objectives (e.g. Webster-Stratton, 2001). Finally, several programmes have addressed specific cognitive control skills over short periods of time (Klingberg, Forssberg \& Westerberg, 2002; Rueda, Rothbart, McCandliss, Saccomanno \& Posner, 2005). In the following sections these programmes will be reviewed in order identify the most promising interventions for enhancing student's classroom engagement.

\section{Tools of the mind}

According to Lev Vygotsky's social learning theory, children's acquisition of new skills occurs most efficiently in the context of social interactions. Specifically, social interactions are seen as facilitating learning through a process referred to as scaffolding. This process involves a more experienced teacher facilitating child acquisition of knowledge by providing graded assistance to children within the "zone of proximal development". As previously discussed, an important outcome of social learning is children's development of self-regulation. For example, through meaningful interactions with caretakers children become increasingly skilled at using private speech to guide their behaviour. The ability to give oneself instructions in order to plan and regulate one's actions is especially important for the accomplishment of self-controlled behaviour.

The Tools of the Mind programme was developed by educational psychologists Bodrova and Leong (1996) and was inspired by Vygotsky's theory of development (1987). The objective of this programme is to improve cognitive control in the form of self-regulation, metacognition, cognitive flexibility, and working memory in children with the aim of facilitating goal-directed planning, problem solving, and learning. An important component of this programme involves teacher scaffolding and children's use of speech, or constructive self-talk, to facilitate cognitive control (Bodrova \& Leong, 2007). For example, teachers can help children develop metacognition or "thinking about thinking" by prompting children to share how they solved a problem or why they chose one course of action over another. Children also develop selfregulation skills by engaging in activities with peers. For example, in one game, one child plays the role of the 'checker' whose role is to monitor (out loud) the work of their partner as they attempt to complete a task. As children become increasingly skilled at monitoring the work of others, teachers can modify the task by asking children to switch from monitoring the work of others to monitoring their own work during a problem solving task. This exercise is designed to help children learn how to internalise speech and language to regulate their own behaviour. 
Children also work on inhibitory control, by participating in a game called Graphics Practice. During this game, children draw different kinds of marks while music is played. They must then stop on a determined cue. Finally, children also develop working memory and cognitive control by engaging in dramatic play. For example, during dramatic play, children are asked to play a role, thus requiring them to update and keep in working memory information that is relevant to their scenario. Furthermore, as children interact with others, they must also use attention control and flexibility in order to help them adapt and rethink their role in light of new developments.

The effectiveness of Tools has been demonstrated with four-year-olds from disadvantaged neighbourhoods (Diamond, Barnett, Thomas \& Munro, 2007). Specifically, when compared to controls, children randomly assigned to follow Tools curriculum performed better on executive function tests one year later. Unfortunately, there are no data available on the effectiveness of this programme from nondisadvantaged children. As such, in order to better understand the potential benefit of implementing this programme on a wider scale, replications with more heterogeneous population-based samples are necessary. Nevertheless, this programme remains promising in light of its effectiveness and ease of implementation within the preschool environment.

\section{Montessori education}

Montessori educational systems were designed to target social and academic skills in children from disadvantaged backgrounds (Lillard, 2005). An evaluation of this programme suggests its effectiveness in promoting cognitive control, moral development, and learning skills. Characteristics of this programme include mixed-aged classrooms, student-directed learning activities, and long periods of uninterrupted play (Bodrova \& Leong, 2007). As in Tools of the Mind, children in Montessori classrooms spend much of their time engaged in self-directed learning activities which require autonomy, creativity, and self-control. These effortful control skills represent important foundations for the development of strong classroom engagement skills.

The effectiveness of this system has been measured by comparing two groups of pre-school aged children who were, or were not, granted access to a Montessori classroom through a random lottery. Though all the participants selfselected themselves for Montessori education, the randomised lottery suggests that differences between these groups reflect differences in the education they received during one year of pre-school. Results of the evaluation indicate that relative to controls, Montessori children scored higher on math problem-solving and phonological awareness by the end of kindergarten (Lillard \& Else-Quest, 2006). In addition, Montessori five-year-olds scored higher on tests of executive functioning and moral reasoning and were less likely to show aggressive behaviour. 


\section{REDI pre-school intervention programme}

The REDI programme involves research-based curricula and instructional strategies which were developed with the specific aim of improving children's cognitive control skills. The contents of this programme have been integrated within larger school readiness interventions, such as Head Start (Bierman et al., 2008). The objective is for children to improve their self-regulatory skills in terms of cognitive and emotional control by listening to stories, playing with puppets, and role playing in the classroom. In addition, teachers are provided with training sessions and supervision to help them develop positive classroom management skills, appropriate praise, warm involvement, emotional coaching, and problem-solving dialogue.

Two randomised controlled studies indicate that the present programme implemented in the classroom setting can increase children's working memory, inhibitory control, and attentional set-shifting (Bierman et al., 2008; Bierman et al., 2008). Furthermore, children who participated in this programme also showed improvements in learning engagement. As in the other interventions, a weakness of the original version of the REDI programme is the absence of a parental component. However, in order to increase the dosage of this programme, an enriched version that includes a parental component, has been developed and has demonstrated favourable results (Bierman et al., 2008).

\section{The Incredible Years programme}

The goal of this programme is to reduce conduct problems in children. This intervention was not directly concerned with the improvement of children's cognitive control skills. However, the Incredible Years does include modules that target productive classroom behaviour (Webster-Stratton, Jamila Reid \& Stoolmiller, 2008).

Both teachers and parents deliver the child component of this programme. Guidance is provided to teachers and parents through training videos, manuals and participation in discussion groups. The child component is administered via multiple mediums including videos, selected readings, collaborative learning exercises, games, and the completion of supervised homework exercises. Learning-related skills are targeted by teachers who encourage students to listen and raise their hand in class. Teachers also help students develop good concentration skills by showing them how to avoid interference in the classroom and by teaching them to take time to check over their work.

Parents help transmit the curriculum by learning positive discipline skills. By learning productive parenting strategies, parents are better able to monitor, set limits, establish learning routines, and avoid using criticism. These skills are believed to help children develop better self-regulatory skills and classroom competence. The benefit of including a parental component is supported by research (Razza et al., 2010). In particular hostile parenting has been associated with lower levels of classroom engagement in elementary school. 
The strengths of the present programme include its inclusion and integration of child, parent, and teacher components and its thoughtfully designed training materials, which can be adapted to individuals from different cultural contexts. Randomised control group studies have demonstrated the effectiveness of The Incredible Years programme (Webster-Stratton et al., 2008). Participation is associated with reductions in teacher-rated problem behaviours and increased academic achievement in at riskchildren. What remains to be examined is whether parental and teacher training in positive discipline strategies enhances the effectiveness of pre-school programmes designed to improve classroom engagement skills.

\section{Additional programmes}

Though the following programmes are small in scope, they describe training interventions that are likely to help strengthen children's ability to sustain focus and concentration in the classroom. They also suggest that relatively brief, child-focused, training interventions can lead to significant improvements in attention and cognitive control. The contributions of the following studies are useful for the development of specific modules to be included within larger scope interventions.

- Working Memory Training Program. Klingberg et al., (2002) examined the efficacy of a programme designed to improve child attention skills by targeting working memory. The exercises in this programme are computer-based and involve training on visual-spatial, backward-digit, and letter span tasks. Over the course of 20 days participants showed improvement in attention in the form of improved reasoning ability and scores on the Stroop-tasks. Participants also showed improvement's on Raven's progressive matrices. One limit of this programme is that it was tested in a sample of five- to seven-year-olds diagnosed with ADHD. Nonetheless, in the same study, the findings were replicated with adults without ADHD. As such, given its effectiveness with a non-clinical adult sample, it is possible that this programme can be adapted to benefit non-ADHD pre-school aged children. Furthermore, the relative simplicity of implementation of the computer exercises and the positive results of the current trial suggest that the inclusion of these exercises can enrich larger scope classroom engagement intervention programmes.

- Attention Training Intervention. The objective of Rueda and colleagues (2005) original training programme was to help prepare monkeys for space flight. By adapting the content of this programme for children, the authors found positive effects of their specific training exercises on subsequent attention skills in four- to six-year-olds. Furthermore, these effects were observed above and beyond the influence of genetic factors, which are known to explain a lot of the variance in cognitive control (Barnes, Dean, Nandam, O'Connell \& Bellgrove, 2011). Training sessions were held over nine days on three modules targeting attention: stimulus anticipation and discrimination, and conflict resolution. Participants performed tasks on a computer to fulfil their training on each module. For stimulus 
anticipation, children learned to anticipate the movement of a duck on a computer screen. For stimulus discrimination, children selected a previously viewed portrait from a group of portraits. Finally, for conflict resolution, children performed a Stroop-like task where they were asked to identify which of two sets contained more elements. Conflict was introduced by presenting a smaller set made up of larger digits (a set of three number nine's) versus a larger set of smaller digits (a set of nine number ones). Evaluations showed that children who underwent the training improved their conflict resolution skills and showed improvements in attention and intelligence relative to controls (Rueda et al., 2005). Research should evaluate the sustainability of the effects over time. Furthermore, it would be useful to determine whether the improvement in attention observed in this programme translate into better task-orientation and focus in the classroom.

\section{Summary}

In sum, specific cognitive control training programmes have been successful in targeting, inhibitory control, cognitive flexibility, planning, reasoning, working memory; and attention skills in pre-school aged children. These skills represent prerequisites for behavioural regulation, task-orientation, persistence, and focus in the classroom. Although no programme has comprehensively targeted classroom engagement as their primary focus, programmes that have addressed specific components of cognitive control in young children have generally led to improvements in children's ability to remain on-task in the classroom.

The success of interventions, such as Tools of the Mind and Montessori, which are administered mainly by teachers, is promising. Many pre-school and elementary school teachers report facing challenges in the classroom due to child behaviour problems and poor self-regulatory skills. Indeed, poor self-regulation on the behalf of children is a factor that contributes to growing rates of teacher burnout (Hastings \& Bham, 2003). Not surprisingly, when surveyed about the student characteristics they favour most, student compliance, attentiveness, sitting still, and listening are among the most common teacher responses (Rimm-Kaufman, Pianta \& Cox, 2000). As such, programmes and curriculum that are easy to administer and which aim to improve engagement are likely to be met with enthusiasm by teachers.

One limitation of current interventions (with the exception of the REDI and Incredible Years) is the absence of parental components. A continued collaboration with parents may further improve the outcomes of promising interventions, especially in light of the findings that early family characteristics are likely to play an important role in the development of school readiness (Mendelsohn et al., 2011). Furthermore, as suggested by research findings, children may benefit from continued support in the home, and the added involvement of their parents in educational interventions. For most programmes one limitation was not following-up the long-term sustainability of their results. Better understanding the durability of these effects can help inform decisions over how and when to implement these programmes. It can also inform 
the introduction of possible booster components. Finally, a promising programme should offer the possibility of more individualised approaches based on specific child characteristics and need. For example, some children may need more training on attention control, while others might need help on working memory, or emotional regulation. In sum, pre-school intervention programmes, which include training exercises organised into modules that target self-regulation, appear promising for improving classroom engagement. It would be ideal for such programmes to include complementary and individualised mutually reinforcing child, parent, and teacher components.

\section{Limitations and future research}

Most of the studies reviewed were conducted with North American samples. Replication with international data and sub-populations presenting higher levels of risk factors are needed. The correlational methodology employed in most of the reviewed studies precludes the possibility of making causal inferences about the relationships between classroom engagement skills and later child outcomes. Nevertheless in most of the reviewed studies, known confounders were taken into account to reduce the possibility of third variable bias.

Finally, future research should examine, which factors can serve as moderators and mediators of the relationship between classroom engagement and later academic adjustment. For instance, teacher characteristics including teaching style would be of potential interest. It may also be informative to examine whether supportive parental practices and positive attitudes towards child education during the school years also play a role in modifying the relationship between engagement and achievement. In particular, poorly engaged children who also have unsupportive parents, may be especially at risk of experiencing negative academic outcomes (Bernier et al., 2010; Blair \& Diamond, 2008; Ladd, Birch \& Buhs, 1999). In addition, peer relations and children's relationships with teachers may also serve as possible mediators of the relation between engagement and later academic adjustment. In particular, disengaged children who are more disruptive may be more likely to face peer rejection. This might, in turn, lead children to develop feelings of anxiety and frustration, which could undermine concentration and academic performance. Furthermore, in future studies it would be useful to apply a more transactional approach in which the bidirectional links between early childhood risk factors and family risk characteristics on subsequent child regulation and school readiness are taken into account. Finally, some research has examined population heterogeneity by looking at subgroups of children that followed distinct trajectories of engagement over time. However, it would also be informative to examine possible subgroup differences in risk factor profiles. As such, future research with similar data should examine whether subgroups of at-risk children can be identified and whether these subgroups follow different courses of academic adjustment over time. 


\section{Conclusion}

The current crisis in education demands that we increase our ability to understand which skills, if targeted, are likely to bring about improvements in children's academic performance, high school completion, and eventual productivity in the workplace. Taken together, several studies provide evidence that considering classroom engagement skills in terms of the ability to work autonomously and follow directions, can predict later academic performance and psychosocial adjustment, even while adjusting for kindergarten math and verbal skills, and family risk characteristics. This review also suggests a robust association between early cognitive control skills and the development of kindergarten classroom engagement skills. Finally, individual differences in engagement were observed over the course of elementary school suggesting that children presenting cognitive and familial risks in early childhood may be more likely to show low engagement across the grade school years. The present findings therefore suggest that assessing classroom engagement skills at school entry may represent as useful strategy for identifying children who face risks for both academic and psychosocial adjustment problems in later elementary school.

Upon merging scholarship in the fields of education and cognitive neuroscience, we propose that productive work habits in the classroom are likely to represent ecological manifestations of cognitive control skills. Such skills help individuals suppress automatic and less effortful responses in favour of more deliberate and thoughtful actions (Diamond, 2006). Furthermore, from an educational perspective, engagement represents an important mechanism of achievement because it is directly related to being on-task and following directions in the classroom (Fredricks et al., 2004).

An examination of the outcomes and antecedents of classroom engagement also support a conceptualisation of engagement as a contextual manifestation of selfregulation. For one, better classroom engagement was predictive of academic and psychosocial adjustment, both of which have also been shown to rely on child cognitive and emotional regulation. Second, measures of working memory and impulsivity were predictive of classroom engagement skills (Razza et al., 2010). This relationship was robust and revealed no mediation by intellectual skills and socioeconomic factors.

From a policy standpoint the present findings are promising. First, cognitive control appears to play a role in achievement beyond that of IQ and socioeconomic status. Second, research on cognitive control is generally conducted in a controlled laboratory setting. However, studying engagement in the classroom setting, as observed by teachers can help us understand how children's actual contextual application of effortful control is related to later outcomes. Third, in addition to being related to academic outcomes, classroom engagement skills also contribute to better psychosocial and interpersonal adjustment. Finally, classroom engagement skills are malleable and amenable to interventions. How children begin their educational journey has important repercussions on their academic experience, and eventual quality of life. The current review provides evidence that assessing classroom engagement skills can help identify at-risk children. This represents an important step to ensure that all 
children have the opportunity to start school on the right foot and experience success to their full potential.

\section{References}

Aarnoudse-Moens, C., Weisglas-Kuperus, N., Goudoever, J. \& Oosterlaan, J. (2009). Academic achievement, behavioral problems and executive function in very preterm and/or very low birth weight children: A meta-analysis. Acta Pcediatrica, 124: 717-728.

Alexander, K. L., Entwisle, D. R. \& Dauber, S. L. (1993). First-grade classroom behavior: Its short- and long-term consequences for school performance. Child Development, 64: 801-814.

Alexander, K. L., Entwisle, D. R. \& Horsey, C. S. (1997). From first grade forward: Early foundations of high school dropout. Sociology of Education, 70: 87-107.

Almlund, M., Duckworth, A. L., Heckman, J. J. \& Kautz, T. (2011). Personality psychology and economics. In: E. A. Hanushek, S. Machin \& L. Wößmann (eds.), Handbook of the economics of education. Amsterdam: Elsevier.

Altemeier, L., Abbott, R. \& Berninger, V. (2008). Executive functions for reading and writing in typical literacy development and dyslexia. Journal of Clinical and Experimental Neuropsychology, 30: 588-606.

Altemeier, L., Jones, J., Abbott, R. \& Berninger, V. (2006). Executive functions in becoming writing readers and reading writers: Note taking and report writing in third and fifth graders. Developmental Neuropsychology, 29: 161-173.

Archambault, I., Janosz, M., Fallu, J. S. \& Pagani, L. S. (2009). Student engagement and its relationship with early high school dropout. Journal of Adolescence, 32: 651-670.

Baker, J. (2006). Contributions of teacher-child relationships to positive school adjustment during elementary school. Journal of School Psychology, 44: 211-229.

Barkley, R. A. (2004). Attention-deficity /hyperectivity disorder and self-regulation: Taking an evolutionary perspective on executive functioning. In: R. F. Baumeister \& K. D. Vohs (eds.), Handbook of self-regulation: Research, theory, and applications (pp. 301-323). New York: NY: The Guilford Press.

Barkley, R. A. (1997). Behavioral inhibition, sustained attention, and executive functions: Constructing a unifying theory of ADHD. Psychological Bulletin, 121: 65-94.

Barnes, J. J. M., Dean, A. J., Nandam, L. S., O’Connell, R. G. \& Bellgrove, M. A. (2011). The Molecular genetics of executive function: Role of monoamine system genes. Biological Psychiatry, 69: e127-e143.

Barry, T. D., Dunlap, S. T., Cotten, S. J., Lochman, J. E. \& Wells, K. C. (2005). The influence of maternal stress and distress on disruptive behavior problems in boys. Journal of the American Academy of Child \& Adolescent Psychiatry, 44: 265-273. 
Belsky, J., Pasco Fearon, R. M. \& Bell, B. (2007). Parenting, attention and externalizing problems: Testing mediation longitudinally, repeatedly and reciprocally. Journal of Child Psychology and Psychiatry, 48: 1233-1242.

Bergman, L. R., Magnusson, D. \& El-Khouri, B. (2003). Studying individual development in an interindividual context: A person-oriented approach. Mahwah, NJ: Erlbaum.

Bernier, A., Carlson, S. \& Whipple, N. (2010). From external regulation to self-regulation: Early parenting precursors of young children's executive functioning. Child Development, 81(1): 326-339.

Bierman, K. L., Domitrovich, C. E., Nix, R. L., Gest, S. D., Welsh, J. A., Greenberg, M. T., . .. Gill, S. (2008). Promoting academic and social-emotional school readiness: The Head Start REDI programme. Child Development, 79: 1802-1817.

Bierman, K. L., Nix, R. L., Greenberg, M. T., Blair, C. \& Domitrovich, C. E. (2008). Executive functions and school readiness intervention: Impact, moderation, and mediation in the Head Start REDI programme. Development and Psychopathology, 20: $821-843$.

Blair, C. (2002). School readiness: Integrating cognition and emotion in a neurobiological conceptualization of children's functioning at school entry. American Psychologist, 57: 111-135.

Blair, C. \& Diamond, A. (2008). Biological processes in prevention and intervention: The promotion of self-regulation as a means of preventing school failure. Development and Psychopathology, 20: 899-911.

Blair, C., Granger, D. \& Razza, R. P. (2005). Cortisol reactivity is positively related to executive function in preschool children attending Head Start. Child Development, 76: 554-567.

Blair, C. \& Razza, R. P. (2007). Relating effortful control, executive function, and false belief understanding to emerging math and literacy ability in kindergarten. Child Development, 78: 647-663.

Bodrova, E. \& Leong, D. (2007). Tools of the mind: The Vygotskian approach to early childhood education. New York: Merrill/Prentice Hall.

Bowlby, G. (2008). Provincial drop-out rates:trends and consequences. Labor Force Survey. [Online.] Available from: http://www.statcan.gc.ca/pub/81-004x/2005004/8984-eng.htm\#b. (Accessed 1 July 2011.)

Brendgen, M., Wanner, B. \& Vitaro, F. (2006). Verbal abuse by the teacher and child adjustment from kindergarten through grade 6. Pediatrics, 117: 1585-1598.

Bronfenbrenner, U. (1986). Ecology of the family as a context for human development: Research perspectives. Developmental Psychology, 22: 723-742.

Buckhalt, J. A., El Sheikh, M. \& Keller, P. (2007). Children's sleep and cognitive functioning: race and socioeconomic status as moderators of effects. Child Development, 78: 213-231. 
Bull, R. \& Scerif, G. (2001). Executive functioning as a predictor of children's mathematics ability: Inhibition, switching, and working memory. Developmental Neuropsychology, 19: 273-293.

Butterworth, B., Varma, S. \& Laurillard, D. (2011). Dyscalculia: From brain to education. Science, 332: 1049-1053.

Card, D. (1999). The causal effect of education on earnings. In: O. Ashenfelter \& D. Card (eds.), The handbook of labor economics (pp.1801-1864). Amsterdam: North Holland Publishing Company.

Chen, X., Huang, X., Chang, L., Wang, L. \& Li, D. (2010). Aggression, social competence, and academic achievement in Chinese children: A 5-year longitudinal study. Development and Psychopathology, 22: 583-592.

Cicchetti, D. (1984). The emergence of developmental psychopathology. Child Development, 55: 1-7.

Cirino, P. T. (2010). The interrelationships of mathematical precursors in kindergarten. Journal of Experimental Child Psychology, 108: 713-733.

Clark, C., Prior, M. \& Kinsella, G. (2002). The relationship between executive function abilities, adaptive behaviour, and academic achievement in children with externalising behaviour problems. Journal of Child Psychology and Psychiatry, 43: 785-796.

Cohen, S., Tyrrell, D. A. \& Smith, A. P. (1993). Negative life events, perceived stress, negative affect, and susceptibility to the common cold. Journal of Personality and Social Psychology, 64: 131-140.

Deci, E. L. \& Ryan, R. M. (2008). Self-determination theory: A macrotheory of human motivation, development, and health. Canadian Psychology/Psychologie canadienne, 49: 182-185.

Diamond, A. (2006). The early development of executive functions. In: E. Bialystock \& F. I. M. Craik (eds.), Lifespan cognition: Mechanisms of change (pp. 70-95). Oxford, England: Oxford University Press.

Diamond, A., Barnett, W. S., Thomas, J. \& Munro, S. (2007). Preschool programme improves cognitive control. Science, 318: 1387-1388.

Duckworth, A. L. \& Seligman, M. E. P. (2006). Self-discipline gives girls the edge: Gender in self-discipline, grades, and achievement test scores. Journal of Educational Psychology, 98: 198-208.

Duckworth, A. L. \& Seligman, M. E. P. (2005). Self-discipline outdoes IQ in predicting academic performance of adolescents. Psychological Science, 16: 939-944.

Duncan, G. J., Dowsett, C. J., Claessens, A., Magnuson, K., Huston, A. C., Klebanov, P., . .. Brooks-Gunn, J. (2007). School readiness and later achievement. Developmental Psychology, 43: 1428-1446. 
Eccles, J. S., Midgley, C., Wigfield, A., Buchanan, C. M., Reuman, D., Flanagan, C. \& Maclver, D. (1993). Development during adolescence: The impact of stageenvironment fit on young adolescents' experiences in schools and in families. American Psychologist, 48: 90-101.

Ednick, M., Cohen, A. P., McPhail, G. L., Beebe, D., Simakajornboon, N. \& Amin, R. S. (2009). A review of the effects of sleep during the first year of life on cognitive, psychomotor, and temperament development. Sleep, 32: 1449-1458.

Eisenberg, N., Cumberland, A., Spinrad, T. L., Fabes, R. A., Shepard, S. A., Reiser, M., ... Guthrie, I. K. (2001). The relations of regulation and emotionality to children's externalizing and internalizing problem behavior. Child Development, 72: 1112-1134.

Ellickson, P. L. \& McGuigan, K. A. (2000). Early predictors of adolescent violence. American Journal of Public Health, 90: 566-572.

Entwisle, D. R., Alexander, K. L. \& Olson, L. S. (2005). First grade and educational attainment by age 22: A new story. American Journal of Sociology, 110: 1458-1502.

Erikson, E. H. (1950). Childhood and society. New York: Norton.

Farkas, G. (2003). Cognitive and noncognitive traits and behaviors in stratification processes. Annual Review of Sociology, 29: 541-562.

Feldman, R. (2009). The development of regulatory functions from birth to 5 years: Insights from premature infants. Child Development, 80: 544-561.

Fiscella, K. \& Kitzman, H. (2009). Disparities in academic achievement and health: the intersection of child education and health policy. Pediatrics, 123: 1073-1080.

Fitzpatrick, C. (2012). Kindergarten Classroom Engagement Skills:The Road to Academic Success in Elementary School. Published doctoral thesis, University of Montreal, Montréal.

Fitzpatrick, C. \& Pagani, L. S. (2012). Toddler working memory skills predict kindergarten school readiness. Intelligence, 40: 205-212.

Fredricks, J. A., Blumenfeld, P. C. \& Paris, A. H. (2004). School engagement: Potential of the concept, state of the evidence. Review of Educational Research, 74: 59-109.

Freudenberg, N. \& Ruglis, J. (2007). Reframing school dropout as a public health issue. Preventing Chronic Disease, 4: 1-12.

Garon, N., Bryson, S. E. \& Smith, I. M. (2008). Executive function in preschoolers: A review using an integrative framework. Psychological Bulletin, 134: 31-60.

Grissmer, D. K., Grimm, K. J., Aiyer, S. M., Murrah, W. M. \& Steele, J. S. (2010). Fine motor skills and early comprehension of the world: Two new school readiness indicators. Developmental Psychology, 46: 1008-1017.

Gormley Jr, W. T., Phillips, D. \& Gayer, T. (2008). Preschool programmes can boost school readiness. Science, 320: 1723-1724.

Gottfredson, M. R. \& Hirschi, T. (1990). A general theory of crime. Stanford: Stanford University Press. 
Hamre, B. \& Pianta, R. (2001). Early teacher-child relationships and the trajectory of children's school outcomes through eighth grade. Child Development, 72: 625-638.

Hargreaves, J. R., Morison, L. A., Kim, J. C., Bonell, C. P., Porter, J. D. H., Watts, C., ... Pronyk, P. M. (2008). The association between school attendance, HIV infection and sexual behaviour among young people in rural South Africa. Journal of Epidemiology and Community Health, 62: 113-119.

Hastings, R. \& Bham, M. (2003). The relationship between student behaviour patterns and teacher burnout. School Psychology International, 24: 115-127.

Heckman, J. J. (2007). The economics, technology, and neuroscience of human capability formation. Proceedings of the National Academy of Sciences, 104: 1325013255 .

Heckman, J. J. (2006). Skill formation and the economics of investing in disadvantaged children. Science, 312: 1900-1902.

Henry, B., Caspi, A., Moffitt, T. E., Harrington, H. L. \& Silva, P. A. (1999). Staying in school protects boys with poor self-regulation in childhood from later crime: $A$ longitudinal study. International Journal of Behavioral Development, 23: 1049-1073.

High, P. C. \& The Committee on Early Childhood, Adoption, and Dependent Care and Council on School Health. (2008). School readiness. Pediatrics, 121: e1008-e1015.

Janosz, M., Archambault, I., Morizot, J. \& Pagani, L. S. (2008). School engagement trajectories and their differential predictive relations to dropout. Journal of Social Issues, 64: 21-40.

Klingberg, T., Forssberg, H. \& Westerberg, H. (2002). Training of working memory in children with ADHD. Journal of Clinical and Experimental Neuropsychology, 24: 781791.

Knudsen, E. I., Heckman, J. J., Cameron, J. L. \& Shonkoff, J. P. (2006). Economic, neurobiological, and behavioral perspectives on building America's future workforce. Proceedings of the National Academy of Sciences, 103: 10155-10162.

Ladd, G. W., Birch, S. H. \& Buhs, E. S. (1999). Children's social and scholastic lives in kindergarten: Related spheres of influence? Child Development, 70: 1373-1400.

Ladd, G. W. \& Dinella, L. M. (2009). Continuity and change in early school engagement: Predictive of children's achievement trajectories from first to eighth grade? Journal of Educational Psychology, 101: 190-206.

Lee, S. S., Lahey, B. B., Owens, E. B. \& Hinshaw, S. P. (2008). Few preschool boys and girls with ADHD are well-adjusted during adolescence. Journal of Abnormal Child Psychology, 36: 373-383.

Lemelin, J. P. \& Boivin, M. (2007). Success starts in Grade 1: The importance of school readiness. Quebec Longitudinal Study of Child Development (QLSCD 1998-2010) 4, Institut de la Statistique du Québec.

Levin, H., Belfield, C., Muennig, P. \& Rouse, C. (2007). The costs and benefits of an excellent education for all of America's children. New York: Teacher's College. 
Lillard, A. (2005). Montessori: The science behind the genius. New York: NY: Oxford University Press.

Lillard, A. \& Else-Quest, N. (2006). The early years: Evaluating Montessori education. Science, 313: 1893-1894.

Lupien, S. J., Maheu, F., Tu, M., Fiocco, A. \& Schramek, T. E. (2007). The effects of stress and stress hormones on human cognition: Implications for the field of brain and cognition. Brain and Cognition, 65: 209-237.

Magnusson, D. (1998). The logic and implications of a person-oriented approach. In: R. B. Cairns, L. R. Bergman \& J. Kagan (eds.), Methods and models for studying the individual. Thousand Oaks: Sage.

Marcovitch, S. \& Zelazo, P. D. (2009). A hierarchical competing systems model of the emergence and early development of executive function. Developmental Science, 12: 1-18.

Marsh, R., Gerber, A. J. \& Peterson, B. S. (2008). Neuroimaging studies of normal brain development and their relevance for understanding childhood neuropsychiatric disorders. Journal of the American Academy of Child \& Adolescent Psychiatry, 47: 1233-1251.

Matthews, J. S., Ponitz, C. C. \& Morrison, F. J. (2009). Early gender differences in selfregulation and academic achievement. Journal of Educational Psychology, 101: 689784.

McClelland, M. M., Acock, A. C. \& Morrison, F. J. (2006). The impact of kindergarten learning-related skills on academic trajectories at the end of elementary school. Early Childhood Research Quarterly, 21: 471-490.

McWayne, C. M., Fantuzzo, J. W. \& McDermott, P. A. (2004). Preschool competency in context: an investigation of the unique contribution of child competencies to early academic success. Developmental Psychology, 40: 633-645.

Mendelsohn, A. L., Huberman, H. S., Berkule, S. B., Brockmeyer, C. A., Morrow, L. M. \& Dreyer, B. P. (2011). Primary care strategies for promoting parent-child interactions and school readiness in at-risk families: The Bellevue Project for early language, literacy, and education success. Archives of Pediatrics and Adolescent Medicine, 165: 33-41.

Miner, J. L. \& Clarke-Stewart, K. A. (2008). Trajectories of externalizing behavior from age 2 to age 9: Relations with gender, temperament, ethnicity, parenting, and rater. Developmental Psychology, 44: 771-786.

Ministère de l'éducation, du loisir et du sport (2005). Indicateurs de l'éducation Edition 2005. Québec: Direction générale des services à la gestion.

Ministry of Educaction, Leisure, and Sports. (2010). L'obtention d'un diplôme au secondaire: secteur des jeunes et des adultes. http://www.mels.gouv.qc.ca/. Accessed 1 July, 2011.

Mischel, W., Shoda, Y. \& Rodriguez, M. I. (1989). Delay of gratification in children. Science, 244: 933-938. 
Miyake, A., Friedman, N., Emerson, M., Witzki, A., Howerter, A. \& Wager, T. (2000). The unity and diversity of executive functions and their contributions to complex “frontal lobe" tasks: a latent variable analysis. Cognitive Psychology, 41: 49-100.

Moffitt, T. E. \& Henry, B. (1989). Neuropsychological assessment of executive functions in self-reported delinquents. Development and Psychopathology, 1: 105-118.

Murnane, R. J., Willett, J. B. \& Levy, F. (1995). The growing importance of cognitive skills in wage determination. The Review of Economics and Statistics, 77: 251-266.

Nagin, D. \& Tremblay, R. E. (1999). Trajectories of boys' physical aggression, opposition, and hyperactivity on the path to physically violent and nonviolent juvenile delinquency. Child Development, 70: 1181-1196.

Normandeau, S. \& Guay, F. (1998). Preschool behavior and first-grade school achievement: The mediational role of cognitive self-control. Journal of Educational Psychology, 90: 111-121.

Pagani, L. S., Fitzpatrick, C., Archambault, I. \& Janosz, M. (2010). School readiness and later achievement: A French Canadian replication and extension. Developmental Psychology, 46: 984-994.

Pagani, L. S., Tremblay, R. E., Vitaro, F., Boulerice, B. \& McDuff, P. (2001). Effects of grade retention on academic performance and behavioral development. Development and Psychopathology, 13: 297-315.

Pagani, L. S., Vitaro, F., Tremblay, R., McDuff, P., Japel, C. \& Larose, S. (2008). When predictions fail: The case of unexpected pathways toward high school dropout. Journal of Social Issues, 64: 175-194.

Piaget, J. \& Inhelder, B. (1956). The child's conception of space. London: Routledge and Kegan Paul.

Putnam, S. P., Rothbart, M. K. \& Gartstein, M. A. (2008). Homotypic and heterotypic continuity of fine-grained temperament during infancy, toddlerhood, and early childhood. Infant and Child Development, 17: 387-405.

Razza, R. A., Martin, A. \& Brooks-Gunn, J. (2010). Associations among family environment, sustained attention, and school readiness for low-income children. Developmental Psychology, 46: 1528-1542.

Richters, J. E. (1997). The Hubble hypothesis and the developmentalist's dilemma. Development and Psychopathology, 9: 193-229.

Rimm-Kaufman, S., Pianta, R. \& Cox, M. (2000). Teachers' judgments of problems in the transition to kindergarten. Early Childhood Research Quarterly, 15: 147-166.

Rimm-Kaufman, S. E., La Paro, K. M., Downer, J. T. \& Pianta, R. C. (2005). The contribution of classroom setting and quality of instruction to children's behavior in kindergarten classrooms. The Elementary School Journal, 105: 377-394.

Romano, E., Babchishin, L., Pagani, L. S. \& Kohen, D. (2010). School readiness and later achievement: Replication and extension using a nationwide Canadian survey. Developmental Psychology, 46: 995-1007. 
Rosenthal, R. \& Jacobson, L. (1968). Pygamlion in the calssroom. The Urban Review, 3: 16-20.

Rothbart, M. K. \& Bates, J. E. (2006). Temperament. In: N. Eisenberg (ed.), Handbook of Child Psychology (pp. 99-165). Hoboken: Wiley.

Rueda, M. R., Rothbart, M. K., McCandliss, B. D., Saccomanno, L. \& Posner, M. I. (2005). Training, maturation, and genetic influences on the development of executive attention. Proceedings of the National Academy of Sciences, 102: 14931-14936.

Sabbagh, M. A., Xu, F., Carlson, S. M., Moses, L. J. \& Lee, K. (2006). The development of executive functioning and theory of mind: A comparison of Chinese and US preschoolers. Psychological Science, 17: 74-81.

Shonkoff, J. \& Phillips, D. (2000). From neurons to neighbourhoods: The science of early childhood development. Washington: DC: National Academy Press.

Skinner, E. \& Belmont, M. (1993). Motivation in the classroom: Reciprocal effects of teacher behavior and student engagement across the school year. Journal of Educational Psychology, 85: 571-571.

Slopen, N., Fitzmaurice, G., Williams, D. R. \& Gilman, S. E. (2010). Poverty, food insecurity, and the behavior for childhood internalizing and externalizing disorders. Journal of the American Academy of Child \& Adolescent Psychiatry, 49: 444-452.

Tramontana, M., Hooper, S. \& Selzer, S. (1988). Research on the preschool prediction of later academic achievement: A review. Developmental Review, 8: 89-146.

Tsujimoto, S. (2008). The prefrontal cortex: Functional neural development during early childhood. The Neuroscientist, 14: 345-358.

Vitaro, F., Brendgen, M., Larose, S. \& Tremblay, R. E. (2005). Kindergarten disruptive behaviors, protective factors, and educational achievement by early adulthood. Journal of Educational Psychology, 97: 617-629.

Vygotsky, L. S. (1987). Thinking and speech. In: L. S. Vygotsky, R. W. Rieber (series eds.) \& A. S. Carton (vol ed.). The collected works of L. S. Vygotsky, Vol. 1.: Problems in general psychology (N. Minick, Trans.). New York: Plenum.

Webster-Stratton, C., Jamila Reid, M. \& Stoolmiller, M. (2008). Preventing conduct problems and improving school readiness: Evaluation of the Incredible Years teacher and child training programmes in high-risk schools. Journal of Child Psychology and Psychiatry, 49: 471-488.

Wright, B. R. E., Caspi, A., Moffitt, T. E. \& Silva, P. A. (1999). Low self-control, social bonds, and crime: social causation, social selection, or both? Criminology, 37: 479-514.

Zelazo, P. D. \& Frye, D. (1998). Cognitive complexity and control: II. The development of executive function in childhood. Current Directions in Psychological Science, 7: 121-126. 
Zhou, Q., Hofer, C., Eisenberg, N., Reiser, M., Spinrad, T. L. \& Fabes, R. A. (2007). The developmental trajectories of attention focusing, attentional and behavioral persistence, and externalizing problems during school-age years. Developmental Psychology, 43: 369-384.

Zuckerman, B. \& Halfon, N. (2003). School readiness: an idea whose time has arrived. Pediatrics. 111: 1433-1436. 